\title{
Study of the Dental Survey of Laos Children in Champasak Province, 2019
}

\author{
Jae-Geun $\mathrm{Ka}^{1}$, Ja-Won Cho ${ }^{1}$, Hyun-Jun Yoo ${ }^{1}$, Myung-Gu Lee ${ }^{2}$, Nitthasack Phommavongsa ${ }^{1,3}$, \\ Da-Hui Kim ${ }^{4}$, Chan-Soo Kim ${ }^{1}$ \\ ${ }^{1}$ Department of Preventive Dentistry, College of Dentistry, Dankook University, Cheonan, ${ }^{2}$ Department of Biomedical \\ Chemistry, College of Biomedical \& Health Science, Konkuk University, Chungju, Korea, ${ }^{3}$ Department of Pediatric Dentistry, \\ Faculty of Dentistry, University of Health Science, Vientiane, Laos, ${ }^{4}$ Department of Dental Hygiene, College of Health \\ Science, Dankook University, Cheonan, Korea
}

Objective: The goal of this study is to determine the degree of dental caries experience of children in Champasak Province.

Methods: The authors analyze the oral examination results of 100 primary school, 99 junior high school, and 100 high school students.

Results: The decayed-filled primary teeth index (dft index) of 6-year-old primary school children was 5.30 and their primary tooth dental caries experience rate ( $\mathrm{df}$ rate) was $88.00 \%$. The decayed-filled-missing permanent teeth index (DMFT index) of 12-year-old middle school children was 0.75 and their permanent tooth dental caries experience rate (DMF rate) was $35.35 \%$. The DMFT index of 15-year-old middle school children was 2.20 and their DMF rate was $64.00 \%$.

Conclusion: For the growth of qualitative dental care, the manpower required to meet the needs of people must be assessed and efforts must be made to produce them through appropriate medical education.

Keywords: Champasak Province, dental survey, Laos children

\section{Introduction}

According to the World Health Organization, it was defined as "health is a state of complete physical, mental, and social

\section{Corresponding author Chan-Soo Kim}

E-mail: dkuprev@gmail.com

(iD) https://orcid.org/0000-0002-3073-1950

Received July 15, 2021, Revised September 27, 2021, Accepted September 29, 2021

*This article is an excerpt from Jae-Geun Ka's 2020 doctoral thesis. well-being and not merely the absence of disease or infirmity." [1-4]. In other words, health is not just lack of suffering from disease or weakness, but being well in body, mind, and social life [1-4]. In dental care, self-help is the act of trying to preserve one's oral health and in particular not shortening tooth life [1-4]. Oral health is a factor affecting the quality of one's social life. A major oral disease hindering oral health is dental caries [1-4].

In Laos, the dental delivery system in mainly managed by the communist government, but during evening hours, although not in a big way, it changes to a private dental system. According to market theory, the basic oral diseases due to dental caries or periodontal issues occur predominantly owing to

Copyright (C) 2021. Korean Academy of Preventive Dentistry. All rights reserved.

This is an Open Access article distributed under the terms of the Creative Commons Attribution Non-Commercial License (http://creativecommons.org/licenses/ by-nc/4.0) which permits unrestricted non-commercial use, distribution, and reproduction in any medium, provided the original work is properly cited. 
the lack of public oral health programs $[5,6]$.

In Korea, school oral health departments focus mainly on the prevention of caries and other oral injuries for primary school students. In this regard, they have introduced tooth brushing, fluoride mouthwash gargling, and pit and fissure sealant programs [1-4].

In Laos, the government implemented a project for supplying fluoride-containing salt as an oral health program and a simplified and modified atraumatic restoration treatment (SMART) project. The SMART project is based on the Non-traumatic Caries Removal Prevention and Charging Act, and involves the removal of caries using water devices, not electric devices, and replacing them with glass ionomer cement [7-11].

Accordingly, the author intends to conduct a survey of the dental caries experience of children in Champasak Province and the actual condition of students' oral health. This study can be used as basic data for implementing the Lao government's public oral health project.

\section{Materials and Methods}

\section{Subject}

This study targets 6-year-old primary, 12-year-old middle, and 15-year-old high school children in Champasak Province, Laos, following recommendations of the Lao Dental Association and Lao Office of Education to study school students (Table 1).

\section{Methods}

\section{1) Composition of investigation team}

The research team consisted of thirteen persons, including seven Korean dentists, three Lao dentists, one examination assistant, and two administrative staff. The survey criteria of the survey teams were merged just before the survey.

\section{2) Survey schedule}

The investigation was conducted in two rounds as follows:
First round (urban area): February 7, 2019.

Second round (rural area): February 8, 2019.

\section{3) Survey criteria}

The inspection criteria for inspection of teeth were as follows [12,13]:

1: Healthy teeth: Teeth with no caries lesions or evidence of current caries lesion treatment.

2: Caries: A tooth with lesion showing softened hemorrhoids or free enamel.

3: Experienced cavities: Teeth filled with permanent filler, teeth without cavities around the filling, and teeth with artificial crowns for cavities.

4: Loss of caries experience: A tooth that has lost its permanent denture due to caries or caries treatment. However, abutment of processed dentures is an inexperienced caries tooth.

5: Loss of inexperienced caries: Permanent teeth lost due to causes other than caries (trauma, congenital encephalopathy, periodontal disease, orthodontics) and teeth with caries experience were excluded.

6: Crevice complete tooth: Tooth with clogged tooth groove.

7: Inexperienced caries teeth: Permanent teeth with artificial crowns or bands due to causes other than caries (trauma, aesthetic disorders, denture processing, orthodontics of fixation devices), and teeth with caries experience were excluded.

8: Unseeded teeth.

9: Unrecordable teeth.

\section{4) Statistics processing}

Descriptive statistics were calculated using SPSS version 24.0 after entering the oral examination results using the statistics program EXCEL (version 2016, Microsoft Inc, USA).

For primary school students, the caries experience rate ( $\mathrm{df}$ rate), caries experience attraction index (dft index), caries experience attraction surface index (dfs index), caries attraction rate ( $\mathrm{dt}$ rate), and treatment attraction rate ( $\mathrm{ft}$ rate) were calculated. In addition, for middle school and high school students, the permanent teeth dental caries experience rate (DMF rate), caries experience permanent tooth index (DMFT index),

Table 1. Age and gender distribution of study subjects

\begin{tabular}{|c|c|c|c|c|c|c|c|c|c|}
\hline \multirow{2}{*}{ Students' age } & \multicolumn{3}{|c|}{ Champasak } & \multicolumn{3}{|c|}{ Urban area } & \multicolumn{3}{|c|}{ Rural area } \\
\hline & Total & Male & Female & Total & Male & Female & Total & Male & Female \\
\hline Total & 299 & 118 & 181 & 149 & 56 & 93 & 150 & 62 & 88 \\
\hline 6 years & 100 & 45 & 55 & 50 & 18 & 32 & 50 & 27 & 23 \\
\hline 12 years & 99 & 44 & 55 & 49 & 19 & 30 & 50 & 25 & 25 \\
\hline 15 years & 100 & 29 & 71 & 50 & 19 & 31 & 50 & 10 & 40 \\
\hline
\end{tabular}


Table 2. Primary tooth dental caries experience rate of 6-year-old students in Champasak Province

\begin{tabular}{|c|c|c|c|c|c|c|c|c|c|c|}
\hline \multirow{2}{*}{ Index } & \multirow{2}{*}{ Value } & \multicolumn{3}{|c|}{ Champasak } & \multicolumn{3}{|c|}{ Urban area } & \multicolumn{3}{|c|}{ Rural area } \\
\hline & & Total & Male & Female & Total & Male & Female & Total & Male & Female \\
\hline \multirow[t]{2}{*}{$\mathrm{dt}$} & mean & 5.21 & 5.16 & 5.25 & 5.20 & 5.22 & 5.19 & 5.22 & 5.11 & 5.35 \\
\hline & SD & 3.96 & 4.07 & 3.90 & 4.07 & 4.21 & 4.05 & 3.89 & 4.05 & 3.77 \\
\hline \multirow[t]{2}{*}{$\mathrm{ft}$} & mean & 0.09 & 0.20 & 0.00 & 0.12 & 0.33 & 0.00 & 0.06 & 0.11 & 0.00 \\
\hline & SD & 0.64 & 0.94 & 0.00 & 0.85 & 1.41 & 0.00 & 0.31 & 0.42 & 0.00 \\
\hline \multirow[t]{2}{*}{ dft } & mean & 5.30 & 5.36 & 5.25 & 5.32 & 5.56 & 5.19 & 5.28 & 5.22 & 5.35 \\
\hline & SD & 3.91 & 3.96 & 3.90 & 4.00 & 4.00 & 4.05 & 3.85 & 3.99 & 3.77 \\
\hline \multirow[t]{2}{*}{ ds } & mean & 11.60 & 11.91 & 11.35 & 11.80 & 12.22 & 11.56 & 11.40 & 11.70 & 11.04 \\
\hline & SD & 10.87 & 10.40 & 11.34 & 11.77 & 10.78 & 12.46 & 10.01 & 10.34 & 9.83 \\
\hline \multirow[t]{2}{*}{ fs } & mean & 0.29 & 0.64 & 0.00 & 0.52 & 1.44 & 0.00 & 0.06 & 0.11 & 0.00 \\
\hline & SD & 2.61 & 3.88 & 0.00 & 3.68 & 6.13 & 0.00 & 0.31 & 0.42 & 0.00 \\
\hline \multirow[t]{2}{*}{ dfs } & mean & 11.89 & 12.56 & 11.35 & 12.32 & 13.67 & 11.56 & 11.46 & 11.81 & 11.04 \\
\hline & SD & 10.89 & 10.40 & 11.34 & 11.81 & 10.79 & 12.46 & 9.98 & 10.28 & 9.83 \\
\hline df rate & $\%$ & 88.00 & 91.11 & 85.45 & 88.00 & 94.44 & 84.38 & 88.00 & 88.89 & 86.96 \\
\hline dt rate & $\%$ & 98.30 & 96.27 & 100.00 & 97.74 & 94.00 & 100.00 & 98.86 & 97.87 & 100.00 \\
\hline $\mathrm{ft}$ rate & $\%$ & 1.70 & 3.73 & 0.00 & 2.26 & 6.00 & 0.00 & 1.14 & 2.13 & 0.00 \\
\hline
\end{tabular}

$\mathrm{dt}$ : Number of decayed primary teeth, ft: Number of filled primary teeth for dental caries, dft: Number of primary teeth with caries experience, ds: Number of decayed primary teeth surface, fs: Number of filled primary teeth surface for dental caries, dfs: Number of primary teeth surface with caries experience, $\mathrm{df}$ rate: Primary tooth dental caries experience rate, $\mathrm{dt}$ rate: Decayed primary teeth rate, $\mathrm{ft}$ rate: Filled primary teeth rate.

Table 3. Champasak middle school students' permanent teeth dental caries experience

\begin{tabular}{|c|c|c|c|c|c|c|c|c|c|c|}
\hline \multirow{2}{*}{ Index } & \multirow{2}{*}{ Value } & \multicolumn{3}{|c|}{ Champasak } & \multicolumn{3}{|c|}{ Urban area } & \multicolumn{3}{|c|}{ Rural area } \\
\hline & & Total & Male & Female & Total & Male & Female & Total & Male & Female \\
\hline \multirow[t]{2}{*}{ DT } & mean & 0.62 & 0.48 & 0.73 & 0.98 & 0.84 & 1.07 & 0.26 & 0.20 & 0.32 \\
\hline & $\mathrm{SD}$ & 1.23 & 0.90 & 1.43 & 1.55 & 1.17 & 1.76 & 0.63 & 0.50 & 0.75 \\
\hline \multirow[t]{2}{*}{ FT } & mean & 0.12 & 0.05 & 0.18 & 0.22 & 0.11 & 0.30 & 0.02 & 0.00 & 0.04 \\
\hline & $\mathrm{SD}$ & 0.46 & 0.30 & 0.55 & 0.62 & 0.46 & 0.70 & 0.14 & 0.00 & 0.20 \\
\hline \multirow[t]{2}{*}{ MT } & mean & 0.01 & 0.00 & 0.02 & 0.02 & 0.00 & 0.03 & 0.00 & 0.00 & 0.00 \\
\hline & SD & 0.10 & 0.00 & 0.13 & 0.14 & 0.00 & 0.18 & 0.00 & 0.00 & 0.00 \\
\hline \multirow[t]{2}{*}{ DMFT } & mean & 0.75 & 0.52 & 0.93 & 1.22 & 0.95 & 1.40 & 0.28 & 0.20 & 0.36 \\
\hline & SD & 1.28 & 0.98 & 1.46 & 1.57 & 1.27 & 1.73 & 0.64 & 0.50 & 0.76 \\
\hline \multirow[t]{2}{*}{ DS } & mean & 1.37 & 1.02 & 1.65 & 2.18 & 1.84 & 2.40 & 0.58 & 0.40 & 0.76 \\
\hline & $\mathrm{SD}$ & 3.17 & 2.76 & 3.47 & 4.12 & 3.91 & 4.30 & 1.50 & 1.12 & 1.81 \\
\hline \multirow[t]{2}{*}{ FS } & mean & 0.19 & 0.05 & 0.31 & 0.37 & 0.11 & 0.53 & 0.02 & 0.00 & 0.04 \\
\hline & $\mathrm{SD}$ & 0.78 & 0.30 & 1.00 & 1.07 & 0.46 & 1.31 & 0.14 & 0.00 & 0.20 \\
\hline \multirow[t]{2}{*}{ MS } & mean & 0.05 & 0.00 & 0.09 & 0.10 & 0.00 & 0.17 & 0.00 & 0.00 & 0.00 \\
\hline & $\mathrm{SD}$ & 0.50 & 0.00 & 0.67 & 0.71 & 0.00 & 0.91 & 0.00 & 0.00 & 0.00 \\
\hline \multirow[t]{2}{*}{ DMFS } & mean & 1.62 & 1.07 & 2.05 & 2.65 & 1.95 & 3.10 & 0.60 & 0.40 & 0.80 \\
\hline & $\mathrm{SD}$ & 3.43 & 2.77 & 3.85 & 4.42 & 3.91 & 4.73 & 1.50 & 1.12 & 1.80 \\
\hline DMF rate & $\%$ & 35.35 & 29.55 & 40.00 & 51.02 & 47.37 & 53.33 & 20.00 & 16.00 & 24.00 \\
\hline DT rate & $\%$ & 82.43 & 91.30 & 78.43 & 80.00 & 88.89 & 76.19 & 92.86 & 100.00 & 88.89 \\
\hline FT rate & $\%$ & 16.22 & 8.70 & 19.61 & 18.33 & 11.11 & 21.43 & 7.14 & 0.00 & 11.11 \\
\hline MT rate & $\%$ & 1.35 & 0.00 & 1.96 & 1.67 & 0.00 & 2.38 & 0.00 & 0.00 & 0.00 \\
\hline Mortal rate & $\%$ & 17.57 & 17.39 & 17.65 & 20.00 & 22.22 & 19.05 & 7.14 & 0.00 & 11.11 \\
\hline
\end{tabular}

DT: Number of decayed permanent teeth, FT: Number of filled permanent teeth for dental caries, MT: Number of missing permanent teeth for dental caries, DMFT: Number of permanent teeth with caries experience, DS: Number of decayed permanent teeth surface, FS: Number of filled permanent teeth surface for dental caries, MS: Number of missing permanent teeth surface for dental caries, DMFS: Number of permanent teeth surface with caries experience, DMF rate: Permanent tooth dental caries experience rate, DT rate: Decayed permanent teeth rate, FT rate: Filled permanent teeth rate, MT rate: Missing permanent teeth rate, Mortal rate: Caries fatality rate. 
caries experience permanent tooth surface index (DMFS index), caries permanent tooth rate (DT rate), treatment permanent value rate (FT rate), etc., were calculated.

\section{Results}

\section{Primary tooth dental caries experience rate of 6-year-old school students}

The primary tooth dental caries experience rate of 6-yearold students in Champasak Province is shown in Table 2.

\section{Permanent tooth dental caries experience rate of 12-year-old middle school students}

The permanent tooth dental caries experience rate of 12 year-old students in Champasak Province is shown in Table 3.

\section{Permanent tooth dental caries experience rate of 15-year-old high school students}

Permanent tooth dental caries experience rate of 15 -yearold student in the Champasak Province is shown in Table 4.

\section{Discussion}

In general, children in developed countries are known for their increased intake of soft food and drinks containing much, which leads to increased dental caries. Dental caries occurrence is decreasing in developed countries owing to dietary control methods. However, dental caries is increasing in developed and developing countries owing to increased consumption of fruit drinks, carbonated drinks, and snacks containing sugar [1-4]. Therefore, the author tries to collate the basic data required for starting an oral health program for Laos students.

Laos is divided into the capital city Vientiane and 16 provinces $[14,15]$.

Champasak is a region in southwestern Laos near the border between Thailand and Cambodia. It is one of the three principalities that inherited the Kingdom of Laos from Langshan. The 2015 census shows its population as 694,023 . The capital is Pakse, which took its name from Champasak, the former capital of the Kingdom of Champasak [15].

Table 4. Champasak high school students' permanent teeth dental caries experience

\begin{tabular}{|c|c|c|c|c|c|c|c|c|c|c|}
\hline \multirow{2}{*}{ Index } & \multirow{2}{*}{ Value } & \multicolumn{3}{|c|}{ Champasak } & \multicolumn{3}{|c|}{ Urban area } & \multicolumn{3}{|c|}{ Rural area } \\
\hline & & Total & Male & Female & Total & Male & Female & Total & Male & Female \\
\hline \multirow[t]{2}{*}{ DT } & mean & 1.65 & 1.21 & 1.83 & 1.44 & 1.11 & 1.65 & 1.86 & 1.40 & 1.98 \\
\hline & SD & 2.22 & 1.50 & 2.44 & 2.27 & 1.33 & 2.69 & 2.17 & 1.84 & 2.25 \\
\hline \multirow[t]{2}{*}{$\mathrm{FT}$} & mean & 0.37 & 0.69 & 0.24 & 0.74 & 1.05 & 0.55 & 0.00 & 0.00 & 0.00 \\
\hline & SD & 1.32 & 1.67 & 1.13 & 1.79 & 1.99 & 1.67 & 0.00 & 0.00 & 0.00 \\
\hline \multirow[t]{2}{*}{ MT } & mean & 0.18 & 0.07 & 0.23 & 0.32 & 0.00 & 0.52 & 0.04 & 0.20 & 0.00 \\
\hline & SD & 0.69 & 0.26 & 0.80 & 0.94 & 0.00 & 1.15 & 0.20 & 0.42 & 0.00 \\
\hline \multirow[t]{2}{*}{ DMFT } & mean & 2.20 & 1.97 & 2.30 & 2.50 & 2.16 & 2.71 & 1.90 & 1.60 & 1.98 \\
\hline & SD & 2.49 & 2.04 & 2.66 & 2.78 & 2.19 & 3.10 & 2.15 & 1.78 & 2.25 \\
\hline \multirow[t]{2}{*}{ DS } & mean & 3.44 & 2.21 & 3.94 & 3.64 & 2.42 & 4.39 & 3.24 & 1.80 & 3.60 \\
\hline & SD & 6.18 & 3.42 & 6.96 & 7.52 & 3.88 & 9.04 & 4.53 & 2.44 & 4.87 \\
\hline \multirow[t]{2}{*}{ FS } & mean & 0.48 & 1.00 & 0.27 & 0.96 & 1.53 & 0.61 & 0.00 & 0.00 & 0.00 \\
\hline & $\mathrm{SD}$ & 1.77 & 2.63 & 1.22 & 2.42 & 3.15 & 1.80 & 0.00 & 0.00 & 0.00 \\
\hline \multirow[t]{2}{*}{ MS } & mean & 0.90 & 0.34 & 1.13 & 1.60 & 0.00 & 2.58 & 0.20 & 1.00 & 0.00 \\
\hline & SD & 3.44 & 1.29 & 3.98 & 4.68 & 0.00 & 5.75 & 0.99 & 2.11 & 0.00 \\
\hline \multirow[t]{2}{*}{ DMFS } & mean & 4.82 & 3.55 & 5.34 & 6.20 & 3.95 & 7.58 & 3.44 & 2.80 & 3.60 \\
\hline & SD & 7.19 & 4.01 & 8.11 & 8.95 & 4.49 & 10.65 & 4.54 & 2.94 & 4.87 \\
\hline DMF rate & $\%$ & 64.00 & 65.52 & 63.38 & 66.00 & 68.42 & 64.52 & 62.00 & 60.00 & 62.50 \\
\hline DT rate & $\%$ & 75.00 & 61.40 & 79.75 & 57.60 & 51.22 & 60.71 & 97.89 & 87.50 & 100.00 \\
\hline FT rate & $\%$ & 16.82 & 35.09 & 10.43 & 29.60 & 48.78 & 20.24 & 0.00 & 0.00 & 0.00 \\
\hline MT rate & $\%$ & 8.18 & 3.51 & 9.82 & 12.80 & 0.00 & 19.05 & 2.11 & 12.50 & 0.00 \\
\hline Mortal rate & $\%$ & 22.73 & 10.53 & 26.99 & 30.40 & 9.76 & 40.48 & 12.63 & 12.50 & 12.66 \\
\hline
\end{tabular}

DT: Number of decayed permanent teeth, FT: Number of filled permanent teeth for dental caries, MT: Number of missing permanent teeth for dental caries, DMFT: Number of permanent teeth with caries experience, DS: Number of decayed permanent teeth surface, FS: Number of filled permanent teeth surface for dental caries, MS: Number of missing permanent teeth surface for dental caries, DMFS: Number of permanent teeth surface with caries experience, DMF rate: Permanent tooth dental caries experience rate, DT rate: Decayed permanent teeth rate, FT rate: Filled permanent teeth rate, MT rate: Missing permanent teeth rate, Mortal rate: Caries fatality rate. 
True Chips borders Sarah Week and a half in the north, Sekon in the northeast, Atahu in the east, Cambodia in the south, and Thailand in the west. The Mekong River forms part of the border with neighboring Thailand and includes Si Phan Don ("Sichuan Island") in the southern part of the region bordering Cambodia [15].

Champasak Province has an area of $15,415 \mathrm{~km}^{2}$; the 2015 census shows its population as around 690,000 [15].

The author analyzed the oral examination results of 100 primary school, 99 junior high school, and 100 high school students to determine the degree of dental caries experience of children in the Champasak Province.

For 6-year-old primary school children, the dft index was 5.30 , dfs index was 11.89 , df rate was $88.00 \%$, dt rate was $98.30 \%$, and $\mathrm{ft}$ rate was 1 .

For 12-year-old middle school children, the DMFT index was 0.75 , DMFS index was 1.62, DMF rate was $35.35 \%$, DT rate was $82.43 \%$, FT rate was $16.22 \%$, and caries fatality rate was $17.57 \%$.

For 15-year-old high school children, the DMFT index was 2.20, DMFS index was 4.82, DMF rate was $64.00 \%$, DT rate was $75.00 \%$, FT rate was $16.82 \%$, and caries fatality rate was $22.73 \%$.

The DMFT index of 0.75 for 12 -year-old children in the Champasak area was much lower than that of 2.18 for 12-year-old children nationwide in Laos in 2009; the DMFT index for 15-year-old children was lower than 3.20, the index for the total number of children in Laos in 2009. The degree of caries experience was found to have decreased [16,17].

In a comparison between urban and rural areas, the DMFT index for 12-year-old children was 1.22 in cities and 0.28 in rural areas. As for 15-year-olds, the index was 2.50 in cities and 1.90 in rural areas, indicating high caries experience in urban areas.

Caries experience was found to be high for most of the age groups. The df rate for 6-year-old children was $88 \%$, DMF rate for 12 -year-old children was $35 \%$, and DMF rate for 15 -year-old children was $64 \%$.

In particular, as regards the proportion of untreated caries teeth, the dt rate for 6-year-old children was $98 \%$, while the DT rates were $82 \%$ for 12 -year-old and $75 \%$ for 15 -year-old children. The caries fatality rate was from $18 \%$ to $22 \%$. Thus, a treatment project should be introduced to stop the progression of caries and lower the caries fatality rate.

Laos, which once promoted economic development by introducing a market economy in a communist country, has only one dental college and an insufficient number of oral health assistants who are members of dental care. For the qualitative growth of dental care, the required manpower to meet the needs of the people must be assessed, and efforts must be made to produce them through appropriate medical education.

\section{Conclusion}

The authors analyzed the oral examination results of 100 primary school, 99 junior high school, and 100 high school students to determine the degree of dental caries experiences of children in Champasak Province.

1. For 6-year-old primary school children, the dft index was 5.30 , dfs index was 11.89 , df rate was $88.00 \%$, dt rate was $98.30 \%$, and $\mathrm{ft}$ rate was 1 .

2. For 12-year-old middle school children, the DMFT index was 0.75 , DMFS index was 1.62, DMF rate was $35.35 \%$, DT rate was $82.43 \%$, FT rate was $16.22 \%$, and caries fatality rate was $17.57 \%$.

3. For 15-year-old middle school children, the DMFT index was 2.20, DMFS index was 4.82, DMF rate was $64.00 \%$, DT rate was $75.00 \%$, FT rate was $16.82 \%$, and caries fatality rate was $22.73 \%$.

\section{Conflict of Interest}

No potential conflict of interest relevant to this article was reported.

\section{ORCID}

Jae-Geun Ka, https://orcid.org/0000-0001-7193-5063

Ja-Won Cho, https://orcid.org/0000-0003-1458-0416

Hyun-Jun Yoo, https://orcid.org/0000-0002-0100-8309

Myung-Gu Lee, https://orcid.org/0000-0002-0068-1438

Nitthasack Phommavongsa, https://orcid.org/0000-0002-9436-6358

Da-Hui Kim, https://orcid.org/0000-0003-0226-0212

Chan-Soo Kim, https://orcid.org/0000-0002-3073-1950

\section{References}

1. Kim JB, Choi EG, Moon HS, Kim JB, Kim DK, Lee HS, et al. Public health dentistry. 4th ed. Seoul: Komoonsa; 2004:47-86.

2. Kim JB, Choi EG, Moon HS, Kim JB, Kim DK, Lee HS, et al. Public health dentistry. 5th ed. Seoul: Komoonsa; 2009:1-35, 349-430.

3. Kim JB, Choi EG, Paik DI, Shin SC, Chang KW, Hong SJ, et al. Preventive dentistry. 5th ed. Seoul: Komoonsa; 2009:33-88.

4. Paik DI, Kim HD, Shin SC, Cho JW, Park YD, Kim DK, et al. Clinical preventive dentistry. 5th ed. Seoul: Komoonsa; 2011: 65-80.

5. Yun MH, Kim NY, Na EJ, Cho JW. Clinical study on 3-year-fluo- 
ride Iontophoresis program for Lao children. Int J Clin Prev Dent 2017;13:101-9.

6. Kim NY, Yun MH, Lim TW, Keo S. Three years program on pit and fissure sealant for Laos children. Int J Clin Prev Dent 2016;12:269-6.

7. Park WR, Na EJ, Lim JH, Cho JW. Clinical study on fluoride iontophoresis method for Lao children. Int J Clin Prev Dent 2015;11:107-13.

8. Lim JH, Park WR, Na EJ, Senesombath S. Comparison of a 2-year oral health program using sealant and $1.23 \%$ acidulated phosphate fluoride gel in primary school students of Vientiane, Laos. Int J Clin Prev Dent 2016;12:31-6.

9. Na EJ, Lim JH, Park WR, Cho JW. The effect of 2 years pit and fissure sealant program on Laos children. Int J Clin Prev Dent 2015;11:225-32.

10. Phommavongsa N, Park WR, Kim NY, Na EJ, Yun MH, Shin SC, et al. Effects of application of sealant and fluoride gel application program for elementary school children in Laos for 3 years. Int J Clin Prev Dent 2018;14:81-8.
11. Phommavongsa N, Senesombath S, Lim JH, Kim NY, Park WR, $\mathrm{Na}$ EJ, et al. Dental survey of Vientiane city children in Laos. Int J Clin Prev Dent 2015;11:33-8.

12. Yun SW, Shin SC, Chang YS, Kim HK, Sohn SJ, Kim JK, et al. A survey of dental caries in Mongolia in 2014. Int J Clin Prev Dent 2014;10:165-78.

13. Park JH, Han EK, Lee MG, Cho JW. Dental survey of the adolescent at Gwangju-si for water fluoridation. Int J Clin Prev Dent 2015;11:55-60.

14. Laos Tourism Office [Internet]. Laos: Laos Tourism Office [cited 2020 Oct 29]. Available from: https://www.tourismlaos.org/.

15. Wikipedia. Laos [Internet]. Wikipedia [cited 2020 Oct 29]. Available from: http://en.wikipedia.org/wiki/Laos.

16. FDI World Dental Federation. The Oral Health Atlas-Mapping a neglected global health issue. Geneva: FDI World Dental Federation; 2009:12-39.

17. Lao Dental Association. Lao national oral health survey. Lao Dent J 2013;1:46-133. 